\title{
Growth Assessment of Marine-Derived Fungi in the Presence of Esfenvalerate and its Main Metabolites
}

\author{
Willian G Birolli ${ }^{1}$, Natália Alvarenga ${ }^{1}$, Bruna Vacondio ${ }^{2}$, Mirna H R Seleghim² and André L M Porto ${ }^{1 *}$
}

${ }^{1}$ Laboratório de Química Orgânica e Biocatálise, Instituto de Química de São Carlos, Universidade de São Paulo, Av. João Dagnone, 1100, Ed. Química Ambiental, Jd. Santa Angelina, 13563-120, São Carlos, SP, Brazil.

${ }^{2}$ Departamento de Ecologia e Biologia Evolutiva, Universidade Federal de São Carlos, Via Washington Luís, Km 235, 13565-905, São Carlos, SP, Brazil

\begin{abstract}
The growth and biodegradation potential of marine-derived fungi were evaluated by measuring the radial growth of colonies. It was observed that Penicillium raistrickii CBMAI 931, Aspergillus sydowii CBMAI 935, Cladosporium sp. CBMAI 1237, Microsphaeropsis sp. $\operatorname{Dr}(\mathrm{A}) 6$, Acremonium sp. $\operatorname{Dr}(\mathrm{F}) 1$, Westerdykella sp. $\operatorname{Dr}(\mathrm{M} 2) 4$ and Cladosporium sp. $\operatorname{Dr}(\mathrm{M} 2) 2$ were able to grow and develop in the presence of the pyrethroid insecticide esfenvalerate $(\mathrm{S}, \mathrm{S}$ fenvalerate) and its main metabolites (3-phenoxybenzaldehyde, 3-phenoxybenzoic acid, 3-phenoxybenzyl alcohol and 2-(4-chlorophenyl)-3-methylbutyric acid), showing the possibility of esfenvalerate biodegradation by these strains. The presence of technical grade esfenvalerate and its metabolites caused significant growthinhibition, while fungal development was not affected by the presence of the commercial insecticide SUMIDAN 150 SC in the culture medium. This fact might show that the biodegradation of the esfenvalerate in the commercial insecticide is slower than that of the technical grade active ingredient, since slower biodegradation of esfenvalerate would reduce the concentration of phenolic compounds and thus the growth inhibition. Future studies will focus on the quantitative biodegradation analysis of technical grade esfenvalerate and active ingredient in the commercial insecticide.
\end{abstract}

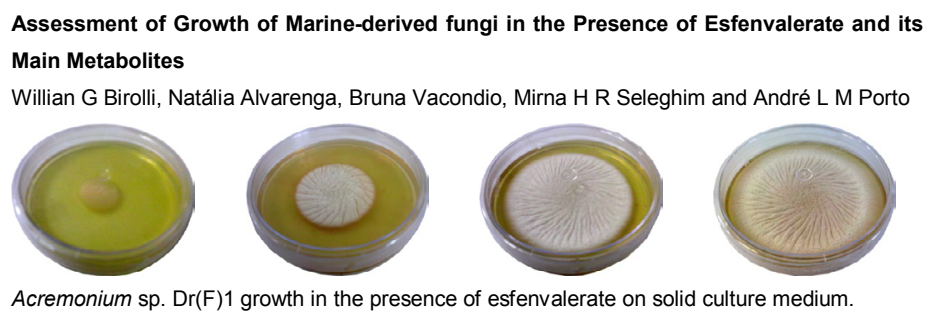

Keywords: Fenvalerate; Marine fungi; Biodegradation; 3-Phenoxybenzoic acid; 3-Phenoxybenzaldehyde

\section{Introduction}

Synthetic pyrethroids have been developed to improve on the specificity and activity of pyrethrin, the natural insecticide produced by the flowers of pyrethrum species (Chrysanthemum cinerariaefolium and coccineum). Pyrethrin is known for its instability in light and air, which limits its effectiveness in crop protection. The synthetic pyrethroids were developed to increase the photostability while retaining the potent and rapid insecticidal activity and relatively low acute mammalian toxicity of pyrethrin. There are about 1000 different structures and some of them are very different from the original pyrethrin structure $[1,2]$.

The structural diversity of synthetic pyrethroids was further enhanced by the discovery that the 2,2-dimethylcyclopropanecarboxylic acid moiety of the pyrethrins and most previous synthetic compounds could be replaced by an $\alpha$-isopropyl phenylacetic acid moiety. This new series of compounds led to the discovery of the commercial insecticide fenvalerate [2].

Fenvalerate is a pesticidal active ingredient composed of four stereoisomers. Originally, a balanced mixture of all four isomers was marketed. However, since the $S, S$-isomer shows the highest insecticidal activity, the synthesis of fenvalerate has been modified to enrich the racemic mixture with the $S, S$-isomer, which is named esfenvalerate [3].

Pyrethroids such as esfenvalerate are esters, with an alcohol and an acid moiety, so that cleavage by esterases is the first step in the biodegradation pathway. Studies available in the literature show that 3-phenoxybenzaldehyde [4,5], 3-phenoxybenzoic acid [5,6], 3-phenoxybenzyl alcohol [7] and 2-(4-chlorophenyl)-3-methylbutyric acid are the main products of pyrethroid biodegradation such as fenvalerate (Figure 1).

Given the capacity of microorganisms to degrade xenobiotics, scientists are exploring the microbial diversity in the search for new catalysts. Marine-derived microorganisms are naturally exposed and adapted to extreme temperature, acidity, high pressure and/or high salt concentration, which are the extreme conditions found in a significant part of the biosphere. Another important characteristic is quick

*Corresponding author: André L M Porto, Instituto de Química de São Carlos Universidade de São Paulo, Laboratório de Química Orgânica e Biocatálise, Av João Dagnone, 1100, Ed. Química Ambiental, Jardim Santa Angelina, 13563-120 São Carlos, SP, Brasil, Tel: +55 163373 8103; Fax: +55 163373 9952; E-mail: almporto@iqsc.usp.br

Received May 03, 2014; Accepted June 10, 2014; Published June 17, 2014

Citation: Birolli WG, Alvarenga N, Vacondio B, Seleghim MHR, Porto ALM (2014) Growth Assessment of Marine-Derived Fungi in the Presence of Esfenvalerate and its Main Metabolites. J Microb Biochem Technol 6: 260-267. doi:10.4172/19485948.1000154

Copyright: $\odot 2014$ Birolli WG, et al. This is an open-access article distributed under the terms of the Creative Commons Attribution License, which permits unrestricted use, distribution, and reproduction in any medium, provided the original author and source are credited 


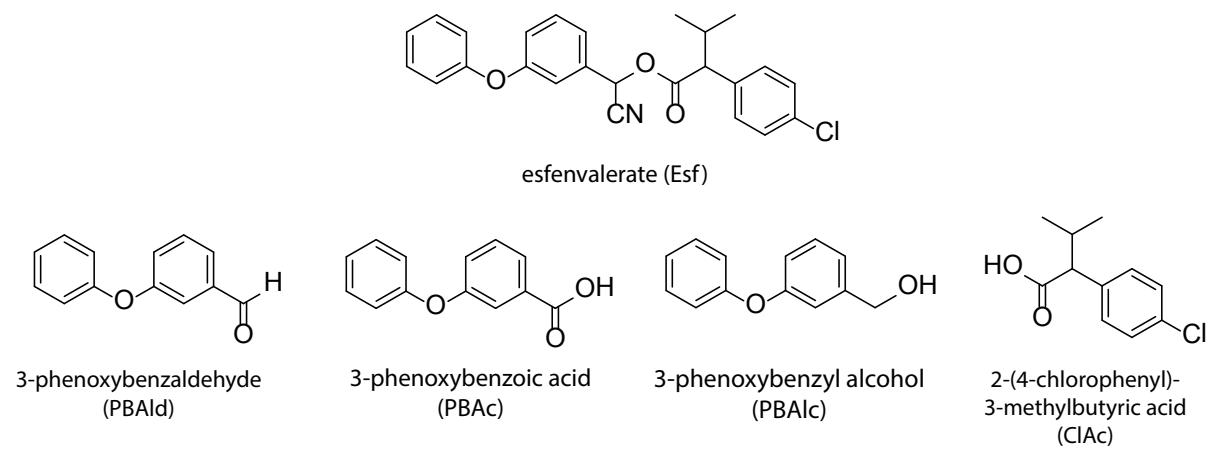

Figure 1: Structure of esfenvalerate and its main metabolites.

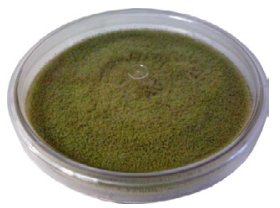

Aspergillus sydowii CBMAI 935

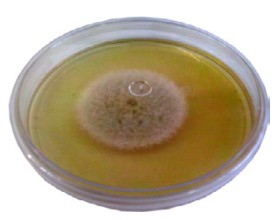

Microsphaeropsis sp. $\operatorname{Dr}(\mathrm{A}) 6$

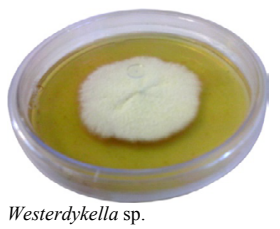

$\operatorname{Dr}(\mathrm{M} 2) 4$

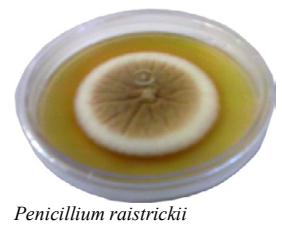

CBMAI 931

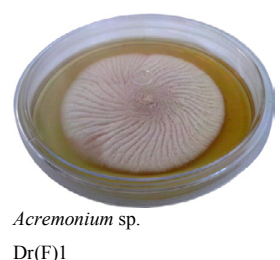

$\operatorname{Dr}(\mathrm{F}) 1$

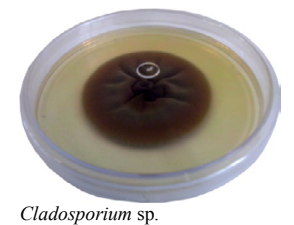

CBMAI 1237

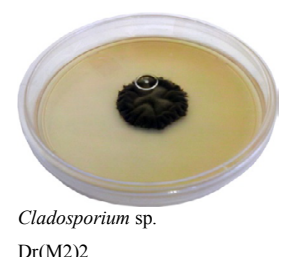

$\operatorname{Dr}(\mathrm{M} 2) 2$

Figure 2: Fungal strains used in this study.

adaptation to environmental change, since marine currents promote rapid temperature and $\mathrm{pH}$ alterations. Marine microorganisms may show efficient biodegradation because they possess a unique enzymatic system adapted to highly halogenated and oxygenated compounds, such as the esfenvalerate employed in this study [8]. Thus, marine-derived fungi might have great potential for bioremediation applications and deserve to be studied.

It is also noteworthy that esfenvalerate has been identified as having the potential to accumulate in aquatic sediments $[9,10]$, making the study of its biodegradation in aquatic systems very important.

Marine-derived fungi have already been used in biodegradation processes. Examples are Aspergillus sclerotiorum CBMAI 849 and Mucor racemosus CBMAI 847, which were capable of metabolizing pyrene to the corresponding pyrenylsulfate and benzo[a]pyrene to benzo[a]pyrenylsulfate [11]. Marine-derived fungi have also been used in the bioremediation of raw textile mill effluents [12], molasses-based raw effluents [13] and the anthraquinone dye, Reactive Blue 4 [14].

Some research on the biodegradation of pesticides by marinederived fungi has been carried out in this laboratory. The organochlorine

insecticide dichlorodiphenyltrichloroethane was biotransformed by Trichoderma sp. [15] and the organophosphate insecticide profenofos [16] by the strains Aspergillus sydowii CBMAI 935 and Penicilium raistrickii CBMAI 931.

The aim of this study was to assess the growth of marinederived fungi in the presence of esfenvalerate ( $S, S$-fenvalerate) and its main biodegradation metabolites [3-phenoxybenzaldehyde, 3-phenoxybenzoic acid, 3-phenoxybenzyl alcohol and 2-(4-chlorophenyl)-3-methylbutyric acid].

\section{Materials and Methods}

\section{Pesticides}

Esfenvalerate technical grade $(92 \%$, EsfTec) and the commercial insecticide Sumidan 150 SC (15\% w/v esfenvalerate, EsfCom) were obtained as a gift from IHARABRAS S.A., it is important to note that Sumidan 150 SC also contains $16 \%$ w/v xylene. 3-Phenoxybenzaldehyde (98\%, PBAld), 3-phenoxybenzoic acid (98\%, PBAc), 3-phenoxybenzyl alcohol (98\%, PBAlc) and 2-(4-chlorophenyl)-3-methylbutyric acid $(98 \%, \mathrm{ClAc})$ were purchased from Sigma-Aldrich.

\section{Marine fungi}

The fungal strains used in this work were collected from marine sponges on the coast of São Sebastião, São Paulo, Brazil by Prof. Roberto G. S. Berlinck (IQSC-USP). The marine-derived fungi Penicillium raistrickii CBMAI 931 and Aspergillus sydowii CBMAI 935 were isolated from the sponge Chelonaplysilla erecta. The fungal strains Cladosporium sp. CBMAI 1237, Microsphaeropsis sp. Dr(A)6, Acremonium sp. Dr(F)1, Westerdykella sp. Dr(M2)4 and Cladosporium sp. $\operatorname{Dr}(\mathrm{M} 2) 2$ were isolated from Dragmacidon reticulata (Figure 2).

\section{Culture media}

Solid medium: Stock cultures of the marine-derived fungi were stored on solid culture medium composed of artificial seawater, agar $\left(20 \mathrm{gL}^{-1}\right)$, malt extract $\left(30 \mathrm{gL}^{-1}\right)$ and soy peptone $\left(3 \mathrm{gL}^{-1}\right)$. The $\mathrm{pH}$ was adjusted to 7 with $0.7 \mathrm{M} \mathrm{NaOH}$ solution, to avoid spontaneous hydrolysis of esfenvalerate. Artificial seawatercomposition was $(1 \mathrm{~L})$ : $\mathrm{CaCl}_{2} .2 \mathrm{H}_{2} \mathrm{O}(1.36 \mathrm{~g}), \mathrm{MgCl}_{2} .6 \mathrm{H}_{2} \mathrm{O}(9.68 \mathrm{~g}), \mathrm{KCl}(0.61 \mathrm{~g}), \mathrm{NaCl}(30.0 \mathrm{~g})$, $\mathrm{Na}_{2} \mathrm{HPO}_{4}(0.014 \mathrm{mg}), \mathrm{Na}_{2} \mathrm{SO}_{4}(3.47 \mathrm{~g}), \mathrm{NaHCO}_{3}(0.17 \mathrm{~g}), \mathrm{KBr}(0.1 \mathrm{~g})$, $\mathrm{SrCl}_{2} \cdot 6 \mathrm{H}_{2} \mathrm{O}(0.040 \mathrm{~g})$ and $\mathrm{H}_{3} \mathrm{BO}_{3}(0.030 \mathrm{~g})$.

The culture medium was sterilized in an autoclave (AV-50, Phoenix, Brazil) at $121^{\circ} \mathrm{C}$ for 20 minutes and manipulations involving marine fungi were carried out in a laminar flow cabinet (FUV-18, Veco, Brazil). Since the microorganisms used in this study were isolated on 
Citation: Birolli WG, Alvarenga N, Vacondio B, Seleghim MHR, Porto ALM (2014) Growth Assessment of Marine-Derived Fungi in the Presence of Esfenvalerate and its Main Metabolites. J Microb Biochem Technol 6: 260-267. doi:10.4172/1948-5948.1000154

various culture media, $3 \%$ malt was used as a nutrient source because it is a rich and appropriate medium for marine microorganisms $[17,18]$.

\section{Growth of marine fungi on solid medium}

Radial growth experiments were performed to assess the development inhibition caused by the presence of xenobiotic compounds. Thus, solid culture media were prepared with esfenvalerate technical grade (EsfTec), esfenvalerate commercial insecticide (EsfCom), xylene, 3-phenoxybenzaldehyde (PBAld), 3-phenoxybenzoic acid (PBAc), 3-phenoxybenzyl alcohol (PBAlc) and 2-(4-chlorophenyl)-3-methylbutyric acid (ClAc).

It is noteworthy that, except for the commercial insecticide, all the xenobiotic compounds were predissolved in $100 \mu \mathrm{L}$ of DMSO per plate to enhance the dissipation of xenobiotic in the culture medium. Xenobiotic was added to the culture medium when the temperature had fallen to $40-50^{\circ} \mathrm{C}$ to prevent thermal degradation of the added compound. The agar plates were inoculated at a central insertion point and the colony diameters were measured after 7, 14, 21 and 28 days of cultivation in an incubator at $32^{\circ} \mathrm{C}$ (B.O.D. 411D, Nova Ética) (Figure 3). Each experiment was carried out in triplicate.

The experiments were performed on the following media:

A. 3\% Malt: Culture medium $(25 \mathrm{~mL})$, without the addition of xenobiotic compounds.

B. $3 \%$ Malt+EsfCom $\left(100 \mathrm{mg} \cdot \mathrm{L}^{-1}\right)$ : Culture medium $(25 \mathrm{~mL})$ with volume of EsfCom (SUMIDAN $150 \mathrm{SC}$ ) providing $100 \mathrm{mgL}^{-1}$ active ingredient.

C. $3 \%$ Malt+DMSO $(100 \mu \mathrm{L})$ : Culture medium $(25 \mathrm{~mL})$ with 100 $\mu \mathrm{L}$ of DMSO.

D. $3 \%$ Malt+Xylene (107 mg. $\mathrm{L}^{-1}$, which is the concentration of xylene when $100 \mathrm{mg} \cdot \mathrm{L}^{-1}$ active ingredient of EsfCom is added): Culture medium $(25 \mathrm{~mL})$ with $3 \mu \mathrm{L}$ of xylene previously dissolved in $100 \mu \mathrm{L}$ of DMSO.

E. $3 \%$ Malt+EsfTec $\left(100 \mathrm{mg} \cdot \mathrm{L}^{-1}\right)$ : Culture medium $(25 \mathrm{~mL})$ with $2.5 \mathrm{mg}$ of EsfTec dissolved in $100 \mu \mathrm{L}$ of DMSO before addition.

F. $3 \%$ Malt+EsfTec (100 mg. $\left.\mathrm{L}^{-1}\right)+$ Xylene (107 mg. $\left.\mathrm{L}^{-1}\right)$ : Culture medium $(25 \mathrm{~mL})$ with $2.5 \mathrm{mg}$ of EsfTec and $3 \mu \mathrm{L}$ of xylene dissolved in $100 \mu \mathrm{L}$ of DMSO.

G. $3 \%$ Malt+ClAc $\left(20 \mathrm{mg} \cdot \mathrm{L}^{-1}\right)$ : Culture medium $(25 \mathrm{~mL})$ with 0.5 $\mathrm{mg}$ of ClAc dissolved in $100 \mu \mathrm{L}$ of DMSO.

H. $3 \%$ Malt+PBAlc (20 mg.L $\left.{ }^{-1}\right)$ : Culture medium $(25 \mathrm{~mL})$ with 0.5 $\mathrm{mg}$ of PBAlc dissolved in $100 \mu \mathrm{L}$ of DMSO.

I. $3 \%$ Malt+PBAc $\left(20\right.$ mg.L $\left.\mathrm{L}^{-1}\right)$ : Culture medium $(25 \mathrm{~mL})$ with 0.5

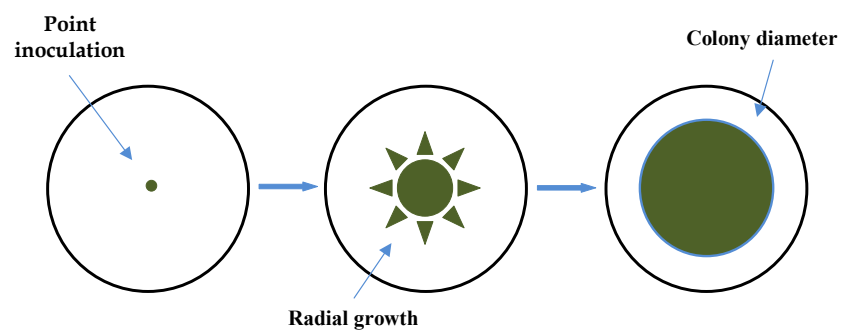

Figure 3: Experiments of colony radial growth. mg of PBAc dissolved in $100 \mu \mathrm{L}$ of DMSO.

J. $3 \%$ Malt+FBAld $\left(20 \mathrm{mg} \cdot \mathrm{L}^{-1}\right)$ : Culture medium $(25 \mathrm{~mL})$ with 0.5 $\mathrm{mg}$ of PBAld dissolved in $100 \mu \mathrm{L}$ of DMSO.

The diameter percentage was calculated according to the equation 1.

$\mathrm{D} \%=(\mathrm{Dx} 100) / \mathrm{D}_{\text {ref }}$ (Equation 1$)$

Where:

$\mathrm{D} \%=$ colony diameter in relation to the reference (\%)

$\mathrm{D}=$ colony diameter $(\mathrm{cm})$

$\mathrm{D}_{\text {ref }}=$ reference colony diameter $(\mathrm{cm})$

\section{Results and Discussion}

Radial growth experiments of marine-derived fungi, not previously used in any study of pyrethroid biodegradation, were performed in the presence of xenobiotics. These experiments were carried out to assess the growth of these strains in the presence of esfenvalerate and its main metabolites, which are known to be toxic and recalcitrant.

In the experiment with the strain Microsphaeropsis sp. $\operatorname{Dr}(\mathrm{A}) 6$ (Table 1, S.I. 1), it was observed during 7 and 14 days of incubation that the presence of the EsfCom had no significant effect on colony growth (Exp. B, 102\% and 104\%, respectively), relative to the growth in 3\% malt in the absence of the insecticide (Exp. A).

However, when xylene (Exp. D), EsfTec (Exp. E) or xylene plus EsfTec (Exp. F) was added to the medium, a smaller colony, with a $75 \%$ diameter of the reference colony diameter (Exp. C) was seen after 7 days of incubation. After 14 days, the growth inhibition was still apparent, but the colony diameter differed from the reference diameter less than after 7 days.

In the presence of the possible metabolites of biodegradation [PBAc (Exp. I), PBAld Exp. (J), PBAlc (Exp. H) and ClAc (Exp. G)] growth inhibition was also seen, with a colony of around $65 \%$ of the reference diameter (Exp. C) after 7 days and $75 \%$ after 14 days.

After 21 days, the fungal colony had grown all over the plate in the reference experiment M3 (Exp. A), EsfCom (Exp. B) and M3+DMSO (Exp. C), while in the presence of xylene (Exp. D), EsfTec (Exp. E), xylene and EsfTec (Exp. F), PBAc (Exp. I), PBAld(Exp. J), PBAlc (Exp. $\mathrm{H}$ ) and $\mathrm{ClAc}$ (Exp. G), the colony was smaller than $8.0 \mathrm{~cm}$. At 28 days, all the colonies covered the entire plate surface.

In the experiment with Westerdykella sp. Dr(M2)4 (Table 2, S.I. 2), during 7, 14, 21 and 28 days of incubation, the presence of EsfCom (Exp. B) had no significant effect on the diameter of the colony, which remained around $110 \%$ of the reference colony size 3\% malt (Exp. A), throughout the experiment.

Xylene (Exp. D) and EsfTec (Exp. E) led to smaller colonies of approximately $60 \%$ of the reference colony size (Exp. C), throughout the assessed period. It was also observed that in the presence of xylene plus EsfTec (Exp. F), the inhibitory effect was additive, inducing the least-developed colony observed, reaching only $33 \%$ of the reference colony diamenter (Exp. C). The presence of ClAc (Exp. G) did not cause any difference from the reference M3+DMSO (Exp. C).

It is important to note that PBAc (I) stimulated the colony growth from 21 days of incubation, resulting in a colony diameter of $124 \%$ of the reference M3+DMSO (C).

In the experiment with the strain Acremonium sp. $\operatorname{Dr}(\mathrm{F}) 1$ (Table 
Citation: Birolli WG, Alvarenga N, Vacondio B, Seleghim MHR, Porto ALM (2014) Growth Assessment of Marine-Derived Fungi in the Presence of Esfenvalerate and its Main Metabolites. J Microb Biochem Technol 6: 260-267. doi:10.4172/1948-5948.1000154

\begin{tabular}{|c|c|c|c|c|c|c|c|c|c|}
\hline \multirow{3}{*}{\multicolumn{2}{|c|}{ Experiment }} & \multicolumn{8}{|c|}{ Time (days) } \\
\hline & & \multicolumn{2}{|l|}{7} & \multicolumn{2}{|l|}{14} & \multicolumn{2}{|l|}{21} & \multicolumn{2}{|l|}{28} \\
\hline & & \multirow{2}{*}{$\begin{array}{l}\mathbf{c m} \\
4.4 \pm 0.3\end{array}$} & \multirow{2}{*}{\begin{tabular}{|l|}
$\%$ \\
Ref.
\end{tabular}} & \multirow{2}{*}{$\begin{array}{l}\text { cm } \\
7.4 \pm 0.4\end{array}$} & \multirow{2}{*}{\begin{tabular}{|l|}
$\%$ \\
Ref.
\end{tabular}} & \multirow{2}{*}{\begin{tabular}{|l|}
$\mathbf{c m}$ \\
$8.0^{c}$
\end{tabular}} & \multirow{2}{*}{\begin{tabular}{|l|}
$\%$ \\
Ref.
\end{tabular}} & \multirow{2}{*}{\begin{tabular}{|l|}
$\mathbf{c m}$ \\
$8.0^{c}$
\end{tabular}} & \multirow{2}{*}{\begin{tabular}{|l|}
$\%$ \\
Ref.
\end{tabular}} \\
\hline A & M3 & & & & & & & & \\
\hline$B$ & M3+EsfCom (100 mg. $\left.\mathrm{L}^{-1}\right)$ & $4.5 \pm 0.1$ & $102^{\mathrm{a}}$ & $7.7 \pm 0.2$ & 104.0 & $8.0^{\mathrm{c}}$ & - & $8.0^{c}$ & - \\
\hline C & M3+DMSO $(100 \mu \mathrm{L})$ & $4.6 \pm 0.1$ & Ref. & $7.5 \pm 0.2$ & Ref. & $8.0^{c}$ & Ref. & $8.0^{c}$ & Ref. \\
\hline $\mathrm{D}$ & M3+Xylene (107 mg. $\left.\mathrm{L}^{-1}\right)$ & $3.5 \pm 0.2$ & $76^{b}$ & $6.6 \pm 0.4$ & $88^{b}$ & $7.4 \pm 0.3$ & - & $8.0^{c}$ & - \\
\hline $\mathrm{E}$ & M3+EsfTec (100 mg. $\left.\mathrm{L}^{-1}\right)$ & $3.4 \pm 0.2$ & $74^{\mathrm{b}}$ & $7.0 \pm 0.4$ & $93^{b}$ & $7.6 \pm 0.4$ & - & $8.0^{c}$ & - \\
\hline$F$ & $\begin{array}{l}\left.\text { M3+EsfTec (100 mg. } \mathrm{L}^{-1}\right) \\
\left.+ \text { Xylene (107 mg. } \mathrm{L}^{-1}\right)\end{array}$ & $3.5 \pm 0.3$ & $76^{b}$ & $6.2 \pm 0.5$ & $83^{b}$ & $7.2 \pm 0.5$ & - & $8.0^{c}$ & - \\
\hline G & $\mathrm{M} 3+\mathrm{ClAc}\left(20 \mathrm{mg} \cdot \mathrm{L}^{-1}\right)$ & $3.3 \pm 0.2$ & $72^{\mathrm{b}}$ & $5.7 \pm 0.3$ & $76^{\mathrm{b}}$ & $6.4 \pm 0.2$ & - & $8.0^{c}$ & - \\
\hline $\mathrm{H}$ & M3+PBAlc (20 mg. $\left.\mathrm{L}^{-1}\right)$ & $2.8 \pm 0.2$ & $61^{b}$ & $5.6 \pm 0.2$ & $75^{b}$ & $6.9 \pm 0.2$ & - & $8.0^{c}$ & - \\
\hline I & M3+PBAc $\left(20 \mathrm{mg}^{-\mathrm{L}^{-1}}\right)$ & $3.0 \pm 0.1$ & $65^{b}$ & $5.2 \pm 0.1$ & $69^{b}$ & $6.8 \pm 0.1$ & - & $8.0^{c}$ & - \\
\hline $\mathrm{J}$ & M3+PBAld $\left(20 \mathrm{mg} \cdot \mathrm{L}^{-1}\right)$ & $2.9 \pm 0.4$ & $63^{b}$ & $5.8 \pm 0.1$ & $77^{\mathrm{b}}$ & $71 \pm 0.3$ & - & $8.0^{c}$ & - \\
\hline
\end{tabular}

aThe reference used was experiment $A: M 3$.

${ }^{\mathrm{b}}$ The reference used was experiment C: M3+DMSO.

'The colony diameter was measured up to $8 \mathrm{~cm}$ because of interaction with the edge of the plate at $9 \mathrm{~cm}$.

Data are means of triplicate \pm standard deviation.

Table 1: Colony diameter of the fungal strain Microsphaeropsis sp. $\operatorname{Dr}(\mathrm{A}) 6$ in growth experiments.

\begin{tabular}{|c|c|c|c|c|c|c|c|c|c|}
\hline \multirow{3}{*}{\multicolumn{2}{|c|}{ Experiment }} & \multicolumn{8}{|c|}{ Time (days) } \\
\hline & & \multicolumn{2}{|l|}{7} & \multicolumn{2}{|l|}{14} & \multicolumn{2}{|l|}{21} & \multicolumn{2}{|l|}{28} \\
\hline & & \multirow{2}{*}{$\begin{array}{l}\mathbf{c m} \\
1.1 \pm 0.1\end{array}$} & & \multirow{2}{*}{$\begin{array}{l}\mathbf{c m} \\
2.2 \pm 0.4\end{array}$} & \multirow{2}{*}{\begin{tabular}{|l|}
$\%$ \\
Ref.
\end{tabular}} & \multirow{2}{*}{$\begin{array}{l}\text { cm } \\
3.4 \pm 0.7\end{array}$} & \multirow{2}{*}{\begin{tabular}{|l|}
$\%$ \\
Ref.
\end{tabular}} & \multirow{2}{*}{$\begin{array}{l}\mathbf{c m} \\
4.5 \pm 1.0\end{array}$} & \multirow{2}{*}{\begin{tabular}{|l|}
$\%$ \\
Ref
\end{tabular}} \\
\hline$A$ & M3 & & & & & & & & \\
\hline B & M3+EsfCom (100 mg. $\left.\mathrm{L}^{-1}\right)$ & $1.2 \pm 0.1$ & $109^{a}$ & $2.4 \pm 0.1$ & 109,0 & $3.8 \pm 0.2$ & 112 & $5.0 \pm 0.2$ & 111 \\
\hline C & M3+DMSO (100 $\mu \mathrm{L})$ & $1.2 \pm 0.2$ & Ref. & $2.5 \pm 0.2$ & Ref. & $4.1 \pm 0.4$ & Ref. & $5.5 \pm 0.6$ & Ref. \\
\hline $\mathrm{D}$ & M3+Xylene (107 mg.L-1) & $0.7 \pm 0.1$ & $58^{b}$ & $1.8 \pm 0.1$ & $72^{b}$ & $2.5 \pm 0.2$ & 61 & $2.7 \pm 0.3$ & 49 \\
\hline$E$ & M3+EsfTec (100 mg.L-1) & $0.8 \pm 0.1$ & $67^{b}$ & $1.4 \pm 0.4$ & $56^{\mathrm{b}}$ & $2.6 \pm 0.2$ & 63 & $3.1 \pm 0.3$ & 56 \\
\hline $\mathrm{F}$ & $\begin{array}{l}\left.\text { M3+EsfTec (100 mg. } \mathrm{L}^{-1}\right) \\
\left.\text { +Xylene (107 mg. } \mathrm{L}^{-1}\right)\end{array}$ & $0.8 \pm 0.1$ & $67^{\mathrm{b}}$ & $1.3 \pm 0.4$ & $52^{\mathrm{b}}$ & $1.7 \pm 0.5$ & 41 & $1.8 \pm 0.5$ & 33 \\
\hline G & $\mathrm{M} 3+\mathrm{CIAc}\left(20 \mathrm{mg} \cdot \mathrm{L}^{-1}\right)$ & $1.2 \pm 0.1$ & $100^{b}$ & $2.5 \pm 0.1$ & $100^{\mathrm{b}}$ & $4.1 \pm 0.3$ & 100 & $5.2 \pm 0.4$ & 94 \\
\hline $\mathrm{H}$ & M3+PBAlc $\left(20 \mathrm{mg}^{-\mathrm{L}^{-1}}\right)$ & $1.0 \pm 0.0$ & $83^{b}$ & $1.9 \pm 0.1$ & $76^{\mathrm{b}}$ & $3.3 \pm 0.3$ & 80 & $4.5 \pm 0.4$ & 82 \\
\hline 1 & M3+PBAc (20 mg. $\left.\mathrm{L}^{-1}\right)$ & $1.2 \pm 0.3$ & $100^{b}$ & $2.7 \pm 0.3$ & $108^{b}$ & $5.1 \pm 0.2$ & 124 & $6.8 \pm 0.3$ & 124 \\
\hline$J$ & M3+PBAld (20 mg.L-1) & $0.9 \pm 0.1$ & $75^{b}$ & $1.9 \pm 0.1$ & $76^{b}$ & $3.9 \pm 0.1$ & 95 & $5.5 \pm 0.2$ & 100 \\
\hline
\end{tabular}

aThe reference used was experiment $A: M 3$.

${ }^{\text {b}}$ The reference used was experiment $\mathrm{C}$ : M3+DMSO

Data are means of triplicate \pm standard deviation.

Table 2: Colony diameter of the fungal strain Westerdykella sp. $\operatorname{Dr}(\mathrm{M} 2) 4$ in growth experiments.

3, S.I. 3), it was observed, at all times up to 21 days of incubation that the presence of EsfCom (Exp. B) slightly stimulated colony growth, resulting in an average diameter of $108 \%$ of that in $3 \%$ malt in the absence of insecticide (Exp. A).

However, when xylene (Exp. D), EsfTec (Exp. E) or xylene plus EsfTec (Exp. F) was added to the medium, after 7 days a smaller colony was observed, approximately $70 \%$ of the size of the reference colony (Exp. C) in the presence of xylene (Exp. D) or EsfTec (Exp. E), and approximately $60 \%$ of the reference size in the presence of xylene plus EsfTec (Exp. F). After 14 days of incubation, the growth inhibition was still present, but the colony diameter reduction relative to the M3+DMSO reference was smaller, approximately $90 \%$.

In the presence of the possible metabolites of biodegradation [PBAc (Exp. I), PBAlc (Exp. H) and ClAc (Exp. G)], growth inhibition was not observed, a colony of approximately $100 \%$ of the reference diameter (Exp. C) being measured after 7 and 14 days of incubation. After 21 days of incubation, growth stimulation was observed, resulting in a colony diameter of $110 \%$ of the reference (Exp. C) diameter.
PBAld (Exp. J) induced significant growth inhibition at the start of the test, resulting in approximately 80,90 and $100 \%$ of the reference colony diamenter after 7, 14 and 21 days of incubation, respectively. After 28 days of incubation, the colony covered the whole plate in all the experiments.

The strain Penicillium raistrickii CBMAI 931 (Table 4, S.I. 4) showed no effects on colony growth caused by incubation in the presence of EsfCom (Exp. B), with a diameter of $100 \%$ of the reference size (Exp. A) at both 7 and 14 days. This species is fast-growing and thus the colony had filled the agar plate by 21 days on all media.

Xylene (Exp. D), EsfTec (Exp. E) and xylene plus EsfTec (Exp. F), all resulted in a colony with diameter approximately $80 \%$ of that of the reference colony (Exp. C), after 7 days. After 14 days, the colony diameter was around $90 \%$ of the reference diameter.

In the presence of the possible metabolites [PBAc (Exp. I), PBAld(Exp. J), PBAlc (Exp. H) and ClAc (Exp. G)], some growth inhibition was observed, with a colony of approximately $90 \%$ of the reference (Exp. C), after 7 days. After 14 days of incubation, no 
Citation: Birolli WG, Alvarenga N, Vacondio B, Seleghim MHR, Porto ALM (2014) Growth Assessment of Marine-Derived Fungi in the Presence of Esfenvalerate and its Main Metabolites. J Microb Biochem Technol 6: 260-267. doi:10.4172/1948-5948.1000154

\begin{tabular}{|c|c|c|c|c|c|c|c|c|c|}
\hline \multirow{2}{*}{\multicolumn{2}{|c|}{ Culture medium }} & \multicolumn{8}{|c|}{ Time (days) } \\
\hline & & \multicolumn{2}{|l|}{7} & \multicolumn{2}{|l|}{14} & \multicolumn{2}{|l|}{21} & \multicolumn{2}{|l|}{28} \\
\hline & & \multirow{2}{*}{\begin{tabular}{|l}
$\mathbf{c m}$ \\
$2.3 \pm 0.1$
\end{tabular}} & \multirow{2}{*}{\begin{tabular}{|l|}
$\%$ \\
Ref.
\end{tabular}} & \multirow{2}{*}{$\begin{array}{l}\mathbf{c m} \\
4.2 \pm 0.3\end{array}$} & \multirow{2}{*}{\begin{tabular}{|l|}
$\%$ \\
Ref.
\end{tabular}} & \multirow{2}{*}{\begin{tabular}{|l|}
$\mathbf{c m}$ \\
$6.5 \pm 0.2$
\end{tabular}} & \multirow{2}{*}{\begin{tabular}{|l|}
$\%$ \\
Ref.
\end{tabular}} & \multirow{2}{*}{$\begin{array}{l}\mathbf{c m} \\
8.0^{c}\end{array}$} & \multirow{2}{*}{\begin{tabular}{|l|}
$\%$ \\
Ref.
\end{tabular}} \\
\hline A & M3 & & & & & & & & \\
\hline$B$ & M3+EsfCom (100 mg. $\left.\mathrm{L}^{-1}\right)$ & $2.4 \pm 0.1$ & $104^{a}$ & $4.6 \pm 0.1$ & $109,0^{\mathrm{a}}$ & $7.0 \pm 0.2$ & $108^{a}$ & $8.0^{c}$ & - \\
\hline C & M3+DMSO (100 $\mu \mathrm{L})$ & $2.4 \pm 0.1$ & Ref. & $4.5 \pm 0.2$ & Ref. & $6.6 \pm 0.1$ & Ref. & $8.0^{c}$ & Ref. \\
\hline $\mathrm{D}$ & M3+Xylene (107 mg.L-1) & $1.8 \pm 0.1$ & $75^{\mathrm{b}}$ & $4.4 \pm 0.1$ & $98^{b}$ & $6.2 \pm 0.2$ & $94^{b}$ & $8.0^{c}$ & - \\
\hline $\mathrm{E}$ & M3+EsfTec (100 mg. $\left.\mathrm{L}^{-1}\right)$ & $1.7 \pm 0.2$ & $71^{\mathrm{b}}$ & $4.1 \pm 0.5$ & $91^{b}$ & $6.0 \pm 0.2$ & $92^{b}$ & $8.0^{c}$ & - \\
\hline $\mathrm{F}$ & $\begin{array}{l}\left.\text { M3+EsfTec (100 mg. } \mathrm{L}^{-1}\right) \\
\left.\text { +Xylene (107 mg. } \mathrm{L}^{-1}\right)\end{array}$ & $1.5 \pm 0.1$ & $63^{b}$ & $4.0 \pm 0.2$ & $89^{b}$ & $5.6 \pm 0.3$ & $85^{b}$ & $8.0^{c}$ & - \\
\hline G & $\mathrm{M} 3+\mathrm{CIAc}\left(20 \mathrm{mg} \cdot \mathrm{L}^{-1}\right)$ & $2.4 \pm 0.1$ & $100^{b}$ & $4.6 \pm 0.1$ & $100^{\mathrm{b}}$ & $7.2 \pm 0.2$ & $109^{b}$ & $8.0^{c}$ & - \\
\hline $\mathrm{H}$ & M3+PBAlc (20 mg. $\left.\mathrm{L}^{-1}\right)$ & $2.2 \pm 0.1$ & $92^{\mathrm{b}}$ & $4.3 \pm 0.2$ & $102^{b}$ & $7.2 \pm 0.1$ & $109^{b}$ & $8.0^{c}$ & - \\
\hline 1 & M3+PBAc (20 mg. $\left.\mathrm{L}^{-1}\right)$ & $2.3 \pm 0.1$ & $96^{b}$ & $4.4 \pm 0.1$ & $98^{b}$ & $7.1 \pm 0.2$ & $107^{b}$ & $8.0^{c}$ & - \\
\hline $\mathrm{J}$ & M3+PBAld $\left(20 \mathrm{mg}^{-\mathrm{L}^{-1}}\right)$ & $2.0 \pm 0.1$ & $83^{b}$ & $4.1 \pm 0.1$ & $91^{b}$ & $6.5 \pm 0.2$ & $98^{b}$ & $8.0^{c}$ & - \\
\hline
\end{tabular}

aThe reference used was experiment $A: M 3$.

${ }^{\mathrm{b}}$ The reference used was experiment $\mathrm{C}$ : M3+DMSO.

${ }^{c}$ The colony diameter was measured up to $8 \mathrm{~cm}$ because of interaction with the edge of the plate at $9 \mathrm{~cm}$.

Data are means of triplicate \pm standard deviation.

Table 3: Colony diameter of the fungal strain Acremonium sp. $\operatorname{Dr}(\mathrm{F}) 1$ in growth experiments.

\begin{tabular}{|c|c|c|c|c|c|c|c|c|c|}
\hline \multirow{3}{*}{\multicolumn{2}{|c|}{ Experiment }} & \multicolumn{8}{|c|}{ Time (days) } \\
\hline & & \multicolumn{2}{|l|}{7} & \multicolumn{2}{|l|}{14} & \multicolumn{2}{|l|}{21} & \multicolumn{2}{|l|}{28} \\
\hline & & \multirow{2}{*}{\begin{tabular}{|l|}
$\mathbf{c m}$ \\
$5.2 \pm 0.1$
\end{tabular}} & \multirow{2}{*}{\begin{tabular}{|l|}
$\%$ \\
Ref.
\end{tabular}} & \multirow{2}{*}{$\begin{array}{l}\mathbf{c m} \\
7.8 \pm 0.2\end{array}$} & \multirow{2}{*}{\begin{tabular}{|l|}
$\%$ \\
Ref. \\
\end{tabular}} & \multirow{2}{*}{\begin{tabular}{|l|}
$\mathbf{c m}$ \\
$8.0^{\circ}$ \\
\end{tabular}} & \multirow{2}{*}{\begin{tabular}{|l|}
$\%$ \\
Ref. \\
\end{tabular}} & \multirow{2}{*}{\begin{tabular}{|l|}
$\mathbf{c m}$ \\
$8.0^{c}$ \\
\end{tabular}} & \multirow{2}{*}{\begin{tabular}{|l|}
$\%$ \\
Ref.
\end{tabular}} \\
\hline A & M3 & & & & & & & & \\
\hline B & M3+EsfCom (100 mg.L-1) & $5.2 \pm 0.2$ & $100^{\mathrm{a}}$ & $7.9 \pm 0.1$ & $101^{\mathrm{a}}$ & $8.0^{c}$ & - & $8.0^{c}$ & - \\
\hline C & M3+DMSO $(100 \mu \mathrm{L})$ & $5.2 \pm 0.2$ & Ref. & $7.9 \pm 0.1$ & Ref. & $8.0^{\circ}$ & Ref. & $8.0^{c}$ & Ref. \\
\hline $\mathrm{D}$ & M3+Xylene (107 mg.L-1) & $4.1 \pm 0.1$ & $79^{b}$ & $7.1 \pm 0.1$ & $90^{\mathrm{b}}$ & $8.0^{c}$ & - & $8.0^{c}$ & - \\
\hline E & M3+EsfTec (100 mg.L-1) & $4.0 \pm 0.2$ & $77^{\mathrm{b}}$ & $7.0 \pm 0.2$ & $89^{b}$ & $8.0^{\circ}$ & - & $8.0^{c}$ & - \\
\hline $\mathrm{F}$ & $\begin{array}{l}\text { M3+EsfTec }\left(100 \mathrm{mg} \cdot \mathrm{L}^{-1}\right) \\
+ \text { Xylene }\left(107 \mathrm{mg} \cdot \mathrm{L}^{-1}\right)\end{array}$ & $4.0 \pm 0.2$ & $77^{\mathrm{b}}$ & $6.8 \pm 0.2$ & $86^{\mathrm{b}}$ & $8.0^{\circ}$ & - & $8.0^{c}$ & - \\
\hline G & $\mathrm{M} 3+\mathrm{ClAc}\left(20 \mathrm{mg} \cdot \mathrm{L}^{-1}\right)$ & $4.6 \pm 0.1$ & $88^{b}$ & $7.7 \pm 0.1$ & $97^{\mathrm{b}}$ & $8.0^{c}$ & - & $8.0^{c}$ & - \\
\hline $\mathrm{H}$ & M3+PBAlc (20 mg. $\left.\mathrm{L}^{-1}\right)$ & $4.5 \pm 0.1$ & $86^{b}$ & $7.6 \pm 0.1$ & $96^{\mathrm{b}}$ & $8.0^{\circ}$ & - & $8.0^{c}$ & - \\
\hline 1 & $\mathrm{M} 3+\mathrm{PBAc}\left(20 \mathrm{mg} \cdot \mathrm{L}^{-1}\right)$ & $4.7 \pm 0.3$ & $90^{\mathrm{b}}$ & $7.7 \pm 0.1$ & $97^{\mathrm{b}}$ & $8.0^{\circ}$ & - & $8.0^{c}$ & - \\
\hline $\mathrm{J}$ & M3+PBAld (20 mg.t-1) & $4.5 \pm 0.1$ & $86^{b}$ & $7.7 \pm 0.1$ & $97^{\mathrm{b}}$ & $8.0^{\circ}$ & - & $8.0^{c}$ & - \\
\hline
\end{tabular}

aThe reference used was experiment $\mathrm{A}: \mathrm{M} 3$.

${ }^{\mathrm{b}}$ The reference used was experiment $\mathrm{C}$ : M3+DMSO.

'The colony diameter was measured up to $8 \mathrm{~cm}$ because of interaction with the edge of the plate at $9 \mathrm{~cm}$.

Data are means of triplicate \pm standard deviation.

Table 4: Colony diameter of the fungal strain Penicillium raistrickii CBMAI 931 in growth experiments.

significant difference was observed between the experiments with possible metabolites (Exp. I, Exp. J, Exp. H and Exp. G) and the M3DMSO reference (Exp. C).

The strain Cladosporium sp. $\operatorname{Dr}(\mathrm{M} 2) 2$ (Table 5, S.I. 5) was not affected by the presence of EsfCom (Exp. B), since it showed the same colony diameter as the reference plate M3 (Exp. A) after 7, 14, 21 and 28 days of incubation.

The presence of xylene (Exp. D) and EsfTec (Exp. E) did not produce a significant difference from the reference experiment M3DMSO (Exp. C), since approximately the same diameter was observed. However, in the presence of xylene plus EsfTec (Exp. F), some growth inhibition occurred, since the colony diameter was about $90 \%$ of the reference size (Exp. C) after 7 days, and approximately 80\% after 14, 21 and 28 days of incubation.

The possible metabolite ClAc (Exp. G) showed weaker growth inhibition, with a colony of $90 \%$ of the reference diameter M3-DMSO
(Exp. C) after 7, 14, 21 and 28 days, while PBAc (Exp. I), PBAld (Exp. J) and PBAlc (Exp. H) showed approximately $80 \%$ of the reference diameter after $7,14,21$ and 28 days.

It is important to note that the strain Cladosporium sp. $\operatorname{Dr}(\mathrm{M} 2) 2$ stopped growing after 14 days of development, even on the reference plates. This strain did not grow well or developed properly on the selected culture medium.

In the experiments with Cladosporium sp. CBMAI 1237 (Table 6, S.I. 6), it was observed that the commercial insecticide generated growth inhibition, since the observed colony diameters in the presence of EsfCom (Exp. B) were 80\% of that of the reference culture on M3 agar (Exp. A).

The presence of xylene (Exp. D), EsfTec (Exp. E) or xylene plus EsfTec (Exp. F) did not affect the growth of the fungus, since approximately the same colony diameter was observed on the reference plate (Exp. C). 
Citation: Birolli WG, Alvarenga N, Vacondio B, Seleghim MHR, Porto ALM (2014) Growth Assessment of Marine-Derived Fungi in the Presence of Esfenvalerate and its Main Metabolites. J Microb Biochem Technol 6: 260-267. doi:10.4172/1948-5948.1000154

\begin{tabular}{|c|c|c|c|c|c|c|c|c|c|}
\hline \multirow{3}{*}{\multicolumn{2}{|c|}{ Experiment }} & \multicolumn{8}{|c|}{ Time (days) } \\
\hline & & \multicolumn{2}{|l|}{7} & \multicolumn{2}{|l|}{14} & \multicolumn{2}{|l|}{21} & \multicolumn{2}{|l|}{28} \\
\hline & & \multirow{2}{*}{$\begin{array}{l}\mathbf{c m} \\
1.9 \pm 0.2\end{array}$} & & \multirow{2}{*}{$\begin{array}{l}\mathbf{c m} \\
3.0 \pm 0.1\end{array}$} & \multirow{2}{*}{\begin{tabular}{|l|}
$\%$ \\
Ref.
\end{tabular}} & \multirow{2}{*}{$\begin{array}{l}\mathbf{c m} \\
3.0 \pm 0.1\end{array}$} & \multirow{2}{*}{\begin{tabular}{|l|}
$\%$ \\
Ref.
\end{tabular}} & \multirow{2}{*}{$\begin{array}{l}\mathbf{c m} \\
3.0 \pm 0.2\end{array}$} & \multirow{2}{*}{\begin{tabular}{|l|}
$\%$ \\
Ref.
\end{tabular}} \\
\hline A & M3 & & & & & & & & \\
\hline B & M3+EsfCom (100 mg.t-1) & $2.0 \pm 0.2$ & $105^{\mathrm{a}}$ & $2.9 \pm 0.1$ & $97^{a}$ & $3.0 \pm 0.2$ & $100^{\mathrm{a}}$ & $3.0 \pm 0.2$ & $100^{\mathrm{a}}$ \\
\hline C & M3+DMSO $(100 \mu \mathrm{L})$ & $2.0 \pm 0.1$ & Ref. & $2.9 \pm 0.2$ & Ref. & $3.0 \pm 0.2$ & Ref. & $3.0 \pm 0.2$ & Ref. \\
\hline $\mathrm{D}$ & M3+Xylene (107 mg.L-1) & $2.0 \pm 0.2$ & $100^{\mathrm{b}}$ & $2.8 \pm 0.1$ & $96^{b}$ & $2.8 \pm 0.1$ & $93^{b}$ & $2.8 \pm 0.1$ & $93^{b}$ \\
\hline $\mathrm{E}$ & M3+EsfTec (100 mg. $\left.\mathrm{L}^{-1}\right)$ & $1.9 \pm 0.1$ & $95^{b}$ & $2.7 \pm 0.2$ & $93^{\mathrm{b}}$ & $2.8 \pm 0.2$ & $93^{b}$ & $2.8 \pm 0.2$ & $93^{b}$ \\
\hline$F$ & $\begin{array}{l}\left.\text { M3+EsfTec (100 mg. } \mathrm{L}^{-1}\right) \\
\text { +Xylene }\left(107 \mathrm{mg} \cdot \mathrm{L}^{-1}\right)\end{array}$ & $1.8 \pm 0.2$ & $90^{\mathrm{b}}$ & $2.4 \pm 0.1$ & $83^{b}$ & $2.4 \pm 0.1$ & $80^{\mathrm{b}}$ & $2.4 \pm 0.1$ & $80^{\mathrm{b}}$ \\
\hline G & $\mathrm{M} 3+\mathrm{CIAc}\left(20 \mathrm{mg} \cdot \mathrm{L}^{-1}\right)$ & $1.9 \pm 0.2$ & $95^{b}$ & $2.6 \pm 0.1$ & $90^{\mathrm{b}}$ & $2.6 \pm 0.1$ & $87^{b}$ & $2.6 \pm 0.1$ & $87^{\mathrm{b}}$ \\
\hline $\mathrm{H}$ & M3+PBAlc (20 mg. $\left.\mathrm{L}^{-1}\right)$ & $1.8 \pm 0.1$ & $90^{b}$ & $2.4 \pm 0.1$ & $76^{\mathrm{b}}$ & $2.5 \pm 0.1$ & $83^{b}$ & $2.5 \pm 0.1$ & $83^{b}$ \\
\hline I & M3+PBAc (20 mg. $\left.\mathrm{L}^{-1}\right)$ & $1.8 \pm 0.2$ & $90^{b}$ & $2.4 \pm 0.1$ & $83^{b}$ & $2.4 \pm 0.1$ & $80^{b}$ & $2.4 \pm 0.1$ & $80^{\mathrm{b}}$ \\
\hline $\mathrm{J}$ & M3+PBAld $\left(20 \mathrm{mg}^{-\mathrm{L}^{-1}}\right)$ & $1.7 \pm 0.1$ & $85^{b}$ & $2.3 \pm 0.1$ & $79^{\mathrm{b}}$ & $2.4 \pm 0.1$ & $80^{b}$ & $2.4 \pm 0.1$ & $80^{\mathrm{b}}$ \\
\hline
\end{tabular}

aThe reference used was experiment $A: M 3$.

'The reference used was experiment C: M3+DMSO.

Data are means of triplicate \pm standard deviation.

Table 5: Colony diameter of the fungal strain Cladosporium sp. $\operatorname{Dr}(\mathrm{M} 2) 2$ in growth experiments.

\begin{tabular}{|c|c|c|c|c|c|c|c|c|c|}
\hline \multirow{3}{*}{\multicolumn{2}{|c|}{ Experiment }} & \multicolumn{8}{|c|}{ Time (days) } \\
\hline & & \multicolumn{2}{|l|}{7} & \multicolumn{2}{|l|}{14} & \multicolumn{2}{|l|}{21} & \multicolumn{2}{|l|}{28} \\
\hline & & \multirow{2}{*}{$\begin{array}{l}\mathbf{c m} \\
2.2 \pm 0.2\end{array}$} & \multirow{2}{*}{\begin{tabular}{|l|}
$\%$ \\
Ref.
\end{tabular}} & \multirow{2}{*}{$\begin{array}{l}\mathbf{c m} \\
4.8 \pm 0.3\end{array}$} & \multirow{2}{*}{\begin{tabular}{|l|}
$\%$ \\
Ref.
\end{tabular}} & \multirow{2}{*}{$\begin{array}{l}\mathbf{c m} \\
6.9 \pm 0.4\end{array}$} & \multirow{2}{*}{\begin{tabular}{|l|}
$\%$ \\
Ref.
\end{tabular}} & \multirow{2}{*}{\begin{tabular}{|l|}
$\mathbf{c m}$ \\
$8.0^{c}$
\end{tabular}} & \multirow{2}{*}{\begin{tabular}{|l|}
$\%$ \\
Ref.
\end{tabular}} \\
\hline A & M3 & & & & & & & & \\
\hline B & M3+EsfCom (100 mg. $\left.\mathrm{L}^{-1}\right)$ & $1.8 \pm 0.1$ & $82^{\mathrm{a}}$ & $3.8 \pm 0.1$ & $79^{a}$ & $5.5 \pm 0.2$ & $80^{\mathrm{a}}$ & $7.0 \pm 0.1$ & - \\
\hline C & M3+DMSO $(100 \mu \mathrm{L})$ & $1.9 \pm 0.1$ & Ref. & $3.9 \pm 0.1$ & Ref. & $5.8 \pm 0.2$ & Ref. & $7.1 \pm 0.4$ & Ref. \\
\hline $\mathrm{D}$ & M3+Xylene (107 mg. $\left.\mathrm{L}^{-1}\right)$ & $2.0 \pm 0.2$ & $105^{b}$ & $4.0 \pm 0.3$ & $102^{\mathrm{b}}$ & $5.9 \pm 0.3$ & $98^{b}$ & $7.2 \pm 0.2$ & $101^{b}$ \\
\hline $\mathrm{E}$ & M3+EsfTec (100 mg.L-1) & $2.0 \pm 0.0$ & $105^{b}$ & $4.1 \pm 0.1$ & $105^{\mathrm{b}}$ & $6.3 \pm 0.1$ & $109^{b}$ & $6.9 \pm 0.8$ & $97^{\mathrm{b}}$ \\
\hline$F$ & $\begin{array}{l}\left.\text { M3+EsfTec (100 mg. } \text { L }^{-1}\right) \\
\text { +Xylene }\left(107 \mathrm{mg} \cdot \mathrm{L}^{-1}\right)\end{array}$ & $2.0 \pm 0.1$ & $105^{b}$ & $4.0 \pm 0.3$ & $102^{\mathrm{b}}$ & $5.8 \pm 0.2$ & $100^{\mathrm{b}}$ & $6.8 \pm 0.4$ & $96^{b}$ \\
\hline G & $\mathrm{M} 3+\mathrm{ClAc}\left(20 \mathrm{mg} \cdot \mathrm{L}^{-1}\right)$ & $1.6 \pm 0.2$ & $84^{\mathrm{b}}$ & $3.5 \pm 0.2$ & $90^{b}$ & $5.1 \pm 0.1$ & $88^{b}$ & $6.7 \pm 0.1$ & $94^{\mathrm{b}}$ \\
\hline $\mathrm{H}$ & M3+PBAlc $\left(20 \mathrm{mg}^{-\mathrm{L}^{-1}}\right)$ & $1.2 \pm 0.1$ & $63^{b}$ & $2.8 \pm 0.1$ & $72^{b}$ & $4.5 \pm 0.3$ & $78^{\mathrm{b}}$ & $6.4 \pm 0.2$ & $90^{\mathrm{b}}$ \\
\hline I & M3+PBAc $\left(20 \mathrm{mg} \cdot \mathrm{L}^{-1}\right)$ & $1.6 \pm 0.1$ & $84^{b}$ & $3.4 \pm 0.1$ & $87^{b}$ & $5.4 \pm 0.1$ & $93^{b}$ & $6.7 \pm 0.6$ & $94^{\mathrm{b}}$ \\
\hline $\mathrm{J}$ & M3+PBAld (20 mg. $\left.\mathrm{L}^{-1}\right)$ & $1.0 \pm 0.2$ & $53^{b}$ & $2.8 \pm 0.2$ & $72^{b}$ & $4.8 \pm 0.2$ & $83^{b}$ & $7.0 \pm 0.4$ & $98^{\mathrm{b}}$ \\
\hline
\end{tabular}

aThe reference used was experiment $A: M 3$

${ }^{\mathrm{b}}$ The reference used was experiment $\mathrm{C}$ : M3+DMSO.

${ }^{\mathrm{C}}$ The colony diameter was measured up to $8 \mathrm{~cm}$ because of interaction with the edge of the plate at $9 \mathrm{~cm}$.

Data are means of triplicate \pm standard deviation.

Table 6: Colony diameter of the fungal strain Cladosporium sp. CBMAI 1237 in growth experiments.

The presence of PBAc (Exp. I) and ClAc (Exp. G) caused growth inhibition; the colony diameter observed being approximately $85 \%$ of the reference diameter after 7 days and approximately $90 \%$ after 14 days of growth. PBAlc (Exp. H) also inhibited the growth of this strain, the colony diameter being about $60,70,80$ and $90 \%$ of the reference M3+DMSO (Exp. C) after 7, 14, 21 and 28 day of incubation, respectively.

PBAld (Exp. J) showed a growth inhibition that fell markebly over the time, with a colony measuring $50,70,80$ and $100 \%$ of the reference diameter on M3-DMSO (Exp. C) after 7, 14, 21 and 28 days, respectively.

In the experiments with the strain Aspergillus sydowii CBMAI 935 (S.I. 7), it was not possible to measure the colony diameter, since secondary colonies spread over the plate as the spores dispersed. However, it was possible to note that, in the presence of the possible esfenvalerate metabolites [ACl (Exp. G), FBAlc (Exp. H), FBAc (Exp. I), and FBAld(Exp. J)], even though the fungus had spread all over the plate, the colony was visibly less dense than the reference on M3DMSO (Exp. C).

Several particular characteristics were observed in the fungal growth in the presence of the xenobiotic compounds under study. Generally, it was observed that the possible metabolite ClAc, showed weaker inhibition effects than the other possible metabolites (PBAc, PBAld and PBAlc), while some strains, such as Westerdykella sp. Dr(M2) 4 and Acremonium sp. Dr(F)1 did not exhibit any inhibitory effects at all for this possible metabolite, with colonies of approximately $100 \%$ of the reference diameter.

The presence of the compound FBAlc caused significant growth inhibition in all the strains [Microsphaeropsis sp. Dr(A)6, Westerdykella sp. $\operatorname{Dr}(\mathrm{M} 2) 4$, Penicillium raistrickii CBMAI 931, Cladosporium sp. Dr(M2)2, Cladosporium sp. CBMAI 1237 and Acremonium sp. Dr(F)1], but it was also observed that this inhibition decreased over time, showing that FBAlc and any other toxic compound generated by its degradation may have been consumed, thus reducing the growth inhibition. 
For the FBAld experiments, the strains [Microsphaeropsis sp. $\operatorname{Dr}(\mathrm{A}) 6$, Westerdykella sp. $\operatorname{Dr}(\mathrm{M} 2) 4$, Acremonium $\operatorname{Dr}(\mathrm{F}) 1$, Penicillium raistrickii CBMAI 931, Cladosporium sp. Dr(M2)2 and Cladosporium sp. CBMAI 1237] showed growth inhibition, which decreased considerably during the period of incubation, as observed in the FBAlc experiments.

PBAc caused growth inhibition in most of the tested fungi [Microsphaeropsis sp. Dr(A)6, Penicillium raistrickii CBMAI 931, Cladosporium sp. Dr(M2)2 and Cladosporium sp. CBMAI 1237]. However, no growth effects were observed for the strain Acremonium sp. $\operatorname{Dr}(\mathrm{F}) 1$ and even growth stimulation was observed in the Westerdykella sp. $\operatorname{Dr}(\mathrm{M} 2) 4$ culture, possibly because of the use of this compound as a carbon source or enzyme effector.

The inhibition caused by ClAc, FBAld, FBAlc and FBAc may be due to the formation of phenolic compounds, which are known for their disinfectant action $[19,20]$, these have been described as metabolites of bacterial biodegradation $[6,21]$ and thus might be produced by fungi too.

Except by Cladosporium sp. CBMAI 1237, all the tested strains were significantly inhibited in the presence of esfenvalerate, xylene and esfenvalerate plus xylene. Growth inhibition by esfenvalerate and xylene can be attributed to the formation of phenolic metabolites by biodegradation, which would produce toxic effects. It was observed that the commercial insecticide SUMIDAN 150 SC did not cause growth inhibition effects, suggesting that the biodegradation of esfenvalerate in the commercial insecticide is slower than that of the technical grade compound. A more efficient biodegradation would generate a higher concentration of phenolic compounds, which are the probable cause of growth inhibition.

Another possibility is that the polysaccharides present in the commercial insecticide stimulate the fungal growth and compensate the growth inhibition generated by phenolic metabolites. However, this is not very likely, since a rich medium (malt 3\%) was used in these experiments.

\section{Conclusions}

The marine fungal strains Penicillium raistrickii CBMAI 931, Aspergillus sydowii CBMAI 935, Cladosporium sp. CBMAI 1237, Microsphaeropsis sp. Dr(A)6, Acremonium sp. $\operatorname{Dr}(\mathrm{F}) 1$, Westerdykella sp. $\operatorname{Dr}(\mathrm{M} 2) 4$ and Cladosporium sp. $\operatorname{Dr}(\mathrm{M} 2) 2$ were grown in the presence of esfenvalerate and its main metabolites, showing the potencial of esfenvalerate biodegradation by these strains. It was observed that technical grade esfenvalerate and its metabolites had inhibitory effects on growth, reducing the size of the colony.

However, the fungal development was not affected by the presence of the commercial insecticide SUMIDAN 150 SC in the culture medium, possibly showing that the biodegradation of esfenvalerate in the commercial insecticide is slower than that in the technical grade compound, since a slower biodegradation of esfenvalerate reduces the concentration of phenolic compounds and thus the growth inhibition. Future studies will focus on the quantitative biodegradation analysis of technical grade esfenvalerate and active ingredient in the commercial insecticide.

\section{Acknowledgements}

A. L. M. Porto is grateful to the Conselho Nacional de Desenvolvimento Científico e Tecnológico (CNPq) and Fundação de Amparo a Pesquisa do Estado de São Paulo (FAPESP) for financial support. W. G. Birolli, N. Alvarenga and $\mathrm{B}$. Vacondio thank CNPq, FAPESP and Coordenação de Aperfeiçoamento
Profissional de Nivel Superior (CAPES) for the scholarships, respectively. The authors express their gratitude to Roberto G. S. Berlinck (IQSC-USP, São Carlos $\mathrm{SP}$, Brazil) for providing the marine microorganisms, Timothy Roberts, who reviewed the English language of this paper and IHARABRAS S.A. for supplying the technical grade esfenvalerate and the commercial insecticide SUMIDAN 150 SC.

\section{References}

1. Soderlund DM, Clark JM, Sheets LP, Mullin LS, Piccirillo VJ, et al. (2002) Mechanisms of pyrethroid neurotoxicity: implications for cumulative risk assessment. Toxicology 171: 3-59.

2. Sogorb MA, Vilanova E (2002) Enzymes involved in the detoxification of organophosphorus, carbamate and pyrethroid insecticides through hydrolysis. Toxicol Lett 128: 215-228.

3. Adelsbach TL, Tjeerdema RS (2003) Chemistry and fate of fenvalerate and esfenvalerate. Rev Environ Contam Toxicol 176: 137-154.

4. Chen S, Hu Q, Hu M, Luo J, Weng Q, et al. (2011) Isolation and characterization of a fungus able to degrade pyrethroids and 3-phenoxybenzaldehyde. Bioresour Technol 102: 8110-8116.

5. Chen S, Yang L, Hu M, Liu J (2011) Biodegradation of fenvalerate and 3-phenoxybenzoic acid by a novel Stenotrophomonas sp. strain ZS-S-01 and its use in bioremediation of contaminated soils. Appl Microbiol Biotechnol 90: 755-767.

6. Wang Bao-zhan, Yun M, Zhou Wei-you, Zheng Jin-wei, Zhu Jian-chun, et al. (2011) "Biodegradation of synthetic pyrethroids by Ochrobactrum tritici strain pyd-1". World Journal of Microbiology and Biotechnology 27: 2315-2324.

7. Farghaly MF, Zayed SM, Soliman SM (2013) Deltamethrin degradation and effects on soil microbial activity. J Environ Sci Health B 48: 575-581.

8. Dash HR, Mangwani N, Chakraborty J, Kumari S, Das S (2013) Marine bacteria: potential candidates for enhanced bioremediation. Appl Microbio Biotechnol 97: 561-571.

9. Heinis LJ, Knuth ML (1992) The mixing, distribution and persistence of esfenvalerate within littoral enclosures. Environmental Toxicology and Chemistry 11: 11-25.

10. Nowell LH, Capel PD, Dileanis PD (1999) "Pesticides in Stream Sediment and Aquatic Biota: Distribution, Trends, and Governing Factors ". CRC Press LLC Boca Raton.

11. Passarini MR, Rodrigues MV, da Silva M, Sette LD (2011) Marine-derived filamentous fungi and their potential application for polycyclic aromatic hydrocarbon bioremediation. Mar Pollut Bull 62: 364-370.

12. Verma AK, Raghukumar C, Verma P, Shouche YS, Naik CG (2010) Four marinederived fungi for bioremediation of raw textile mill effluents. Biodegradation 21: 217-233.

13. Verma AK, Raghukumar C, Naik CG (2011) A novel hybrid technology for remediation of molasses-based raw effluents. Bioresour Technol 102: 2411 2418.

14. Verma AK, Raghukumar C, Parvatkar RR, Naik CG (2012) A Rapid Two-Step Bioremediation of the Anthraquinone Dye, Reactive Blue 4 by a Marine-Derived Fungus. Water Air and Soil Pollution 223: 3499-3509.

15. Ortega SN, Nitschke M, Mouad AM, Landgraf MD, Rezende MO, et al. (2011) Isolation of Brazilian marine fungi capable of growing on DDD pesticide. Biodegradation 22: 43-50.

16. Silva NA, Birolli WG, Seleghim MHR, Porto ALM (2013) In "Applied Bioremediation - Active and Passive Approaches" (Y. Patil, ed.). InTech, Morn Hill.

17. Kjer J, Debbab A, Aly AH, Proksch P (2010) Methods for isolation of marinederived endophytic fungi and their bioactive secondary products. Nat Protoc 5: 479-490.

18. Kossuga MH, Romminger S, Xavier C, Milanetto MC, do Valle MZ, et al. (2012) Evaluating methods for the isolation of marine-derived fungal strains and production of bioactive secondary metabolites. Revista Brasileira de Farmacognosia-Brazilian Journal of Pharmacognosy 22: 257-267. 
Citation: Birolli WG, Alvarenga N, Vacondio B, Seleghim MHR, Porto ALM (2014) Growth Assessment of Marine-Derived Fungi in the Presence of Esfenvalerate and its Main Metabolites. J Microb Biochem Technol 6: 260-267. doi:10.4172/1948-5948.1000154

19. Prescott LM, Harley JP, Klein DA (2002) "Microbiology". McGraw-Hill Higher Education, New York.
20. Tortora GJ (2010) "Microbiology: An introduction". Pearson Education.

21. Tallur PN, Megadi VB, Ninnekar HZ (2008) Biodegradation of cypermethrin by Micrococcus sp. strain CPN 1. Biodegradation 19: 77-82. 